\title{
Cycloid psychoses in the psychosis spectrum: evidence for biochemical differences with schizophrenia
}

This article was published in the following Dove Press journal:

Neuropsychiatric Disease and Treatment

2 August 2016

Number of times this article has been viewed

\author{
Nora WA van de Kerkhof ${ }^{\prime, 2}$ \\ Durk Fekkes 2,3 \\ Frank MMA van der \\ Heijden' \\ Witte JG Hoogendijk ${ }^{2}$ \\ Gerald Stöber ${ }^{4}$ \\ Jos IM Egger ${ }^{1,5,6}$ \\ Willem MA Verhoeven ${ }^{1,2}$
}

'Vincent van Gogh Institute for Psychiatry, Centre of Excellence for Neuropsychiatry, Venray,

${ }^{2}$ Department of Psychiatry,

${ }^{3}$ Department of Clinical Chemistry,

Erasmus University Medical Center,

Rotterdam, The Netherlands;

${ }^{4}$ Department of Psychiatry,

Psychosomatics and Psychotherapy,

University of Würzburg, Würzburg,

Germany; ${ }^{5}$ Behavioural Science

Institute, ${ }^{6}$ Donders Institute for Brain,

Cognition and Behaviour, Radboud

University Nijmegen, Nijmegen,

The Netherlands

Correspondence: Nora WA van de Kerkhof

Vincent van Gogh Institute for Psychiatry, Centre of Excellence for

Neuropsychiatry, Stationsweg 46, 5803

AC Venray, The Netherlands

Tel +3I 478527339

Fax +3। 478527 III

Email nvandekerkhof@vvgi.nl

\begin{abstract}
Cycloid psychoses (CP) differ from schizophrenia regarding symptom profile, course, and prognosis and over many decades they were thought to be a separate entity within the psychosis spectrum. As to schizophrenia, research into the pathophysiology has focused on dopamine, brain-derived neurotrophic factor, and glutamate signaling in which, concerning the latter, the $N$-methyl-d-aspartate receptor plays a crucial role. The present study aims to determine whether CP can biochemically be delineated from schizophrenia. Eighty patients referred for psychotic disorders were assessed with the Comprehensive Assessment of Symptoms and History, and (both at inclusion and after 6 weeks of antipsychotic treatment) with the Positive and Negative Syndrome Scale and Clinical Global Impression. From 58 completers, 33 patients were diagnosed with schizophrenia and ten with CP according to the Diagnostic and Statistical Manual of Mental Disorders, Fourth Edition, and Leonhard criteria, respectively. Fifteen patients were diagnosed with other disorders within the psychosis spectrum. At both time points, blood levels of the dopamine metabolite homovanillic acid, brain-derived neurotrophic factor, and amino acids related to glutamate neurotransmission were measured and compared with a matched control sample. Patients with CP showed a significantly better response to antipsychotic treatment as compared to patients with schizophrenia. In CP, glycine levels were elevated and tryptophan levels were lowered as compared to schizophrenia. Glutamate levels were increased in both patient groups as compared to controls. These results, showing marked differences in both treatment outcome and glutamate-related variable parameters, may point at better neuroplasticity in $\mathrm{CP}$, necessitating demarcation of this subgroup within the psychosis spectrum.

Keywords: cycloid psychoses, schizophrenia, glutamate, glycine, tryptophan, neuroplasticity
\end{abstract}

\section{Introduction}

Over many decades, dopamine (DA) neurotransmission has been thought to be the main mechanism in the pathophysiology of psychotic disorders, and DA receptor antagonists have been demonstrated to be effective in reducing - mainly positive psychotic symptoms. ${ }^{1}$ Subsequent research has disclosed that other neurotransmitter systems, particularly that of glutamate, are associated with negative symptoms and cognitive dysfunctions via the $N$-methyl-d-aspartate (NMDA) receptor. ${ }^{2-5}$

Glutamate is the most abundant excitatory neurotransmitter in human brain, and glutamatergic receptors are involved in regulating neuronal migration, growth, and pruning (ie, neuroplasticity) ${ }^{6,7}$ Glutamate acts at different types of receptors, of which the NMDA receptor is the most investigated. ${ }^{89}$ Glycine acts as a co-agonist at the NMDA receptor and can potentiate glutamatergic neurotransmission..$^{10}$ In contrast, 
antagonizing the NMDA receptor by means of phencyclidine or ketamine induces schizophrenia-like symptoms. ${ }^{11,12}$

These observations have led to the hypothesis that the pathophysiology of schizophrenia is at least partly related to impairment in NMDA neurotransmission. ${ }^{13,14}$ Hence, it seems likely that enhancing NMDA activity might benefit patients with schizophrenia, which could possibly be achieved by administering components targeting the glutamate system. . $^{8,10,15,16}$

Cycloid psychoses (CP) as described by Leonhard in the 1950 s, partly operationalized by Perris and Brockington and included in the International Classification of Diseases, Tenth Edition, as acute polymorphic psychotic disorders, differ from schizophrenia with respect to symptom profile, course, and prognosis. ${ }^{17-20}$ According to Leonhard, three subtypes can be delineated: anxiety-happiness psychosis, confusion psychosis, and motility psychosis, all showing a pleiomorphic symptom profile with intraphasic bipolarity. In general, full recovery is reached without residual negative symptoms or cognitive decline. ${ }^{21-23} \mathrm{CP}$, as such, are not included in the Diagnostic and Statistical Manual of Mental Disorders, Fourth Edition (DSM-IV), although pananxiety, perplexity, and motility disorders have been demonstrated in a substantial percentage of patients. ${ }^{24-30}$ An overview of the characteristics of schizophrenia and CP is presented in Table 1.

Since CP differ significantly from schizophrenia, the hypothesis was formulated that they could also be distinct on their biochemical profile, especially regarding glutamatergic transmission. Therefore, in the present study, peripheral levels of amino acids related to glutamate signaling (ie, glutamate, glycine, and tryptophan) were measured in a group of patients with psychosis spectrum disorders. In addition, levels of brain-derived neurotrophic factor (BDNF) and the DA metabolite homovanillic acid (HVA) were determined, reflecting neuroplasticity and dopaminergic activity, respectively.

\section{Methods}

\section{Patients}

Patients were recruited over a 2.5-year period at the Vincent van Gogh Institute for Psychiatry. Included were adult male and female patients meeting DSM-IV criteria for psychosis spectrum disorders, who required antipsychotic treatment intervention. Intervention was defined as start or switch of antipsychotic agent or use of augmentation strategies. Exclusion criteria were known genetic syndromes or intellectual disability, and somatic or neurologic disorders interfering with treatment as usual. Research was performed in accordance with the Declaration of Helsinki and was approved by the regional ethics committee (METiGG) and board of directors of Vincent van Gogh Institute. Written informed consent was obtained following Dutch ethical guidelines (CCMO registration number NL20469.097.07). After inclusion, all patients were prescribed first-generation antipsychotic (FGA) or second-generation antipsychotic (SGA) agents by their treating psychiatrist following standard professional guidelines. Concomitant treatment with two antipsychotic agents, mood stabilizer, and/or antidepressant was allowed and documented.

During the study period, 194 patients were identified as eligible for inclusion. However, from these 194 patients, 71 were considered unable to provide informed consent because of severity of illness. In another 23 patients, the intended pharmacological intervention was not performed, yielding 100 patients who were eligible for inclusion. Twenty patients refused to participate, mostly because of the need for venipuncture, resulting in a study group of 80 patients. Of them, 58 completed all clinical and biochemical assessments at baseline and after 6 weeks.

\section{Diagnostic procedures}

All patients were assessed by the first author $(\mathrm{NvdK})$ before or within 1 week after start of treatment with antipsychotics. At baseline, the Comprehensive Assessment of Symptoms and History was applied to establish diagnoses according

Table I Characteristic differences between schizophrenia and cycloid psychoses

\begin{tabular}{lll}
\hline & Schizophrenia & Cycloid psychoses \\
\hline Onset & Slow and insidious (weeks to months) & Often acute (hours to days) \\
Age at onset & Adolescence/young adulthood & Any age \\
Symptomatology & Delusions, hallucinations, disorganization, & Perplexity, confusion, mood swings, motility disorders, \\
& negative symptoms & hallucinations, ideas of self-sacrifice \\
Course & Relapsing and remitting, chronic, gradual & Full remission, relapsing course without negative or \\
functional and cognitive decline & cognitive decline \\
Treatment & Unfavorable & Favorable \\
Sex distribution & Antipsychotic agents & Low-potent antipsychotic agents in acute phase, limited \\
& & evidence for maintenance treatment (lithium carbonate) \\
\end{tabular}


to DSM-IV. ${ }^{31}$ The Positive and Negative Syndrome Scale (PANSS) and Clinical Global Impression of Severity and Improvement (CGI-S/I) were used to measure symptom profile and overall disease severity at baseline and after 6 weeks. ${ }^{32,33}$ PANSS cognitive score was calculated according to the procedure as described by Lindenmayer et al. ${ }^{34}$ To establish diagnosis of CP, a symptom checklist according to Leonhard was completed by NvdK and a clinician (MKF Schneider) trained in establishing diagnoses according to Leonhard. ${ }^{26,30,35}$ Final diagnoses were made in a so-called Longitudinal Evaluation of All Data (LEAD) conference, in which all possible and probable cases of $\mathrm{CP}$ were discussed with two experts in the field of CP (GS and $\mathrm{WV}){ }^{36}$

\section{Biochemical analyses Patients}

Blood samples were collected by means of venipuncture between 8 and 10 am at both assessment dates to determine BDNF, HVA, the amino acids glutamate, glycine, and tryptophan, and the ratio between tryptophan and the five large neutral amino acids (LNAAs) competing for the same transport system, being leucine, isoleucine, valine, phenylalanine, and tyrosine (Trp/LNAAs ratio).

Plasma was obtained after centrifugation of ethylenediaminetetraacetic acid blood for 20 minutes at 2,650× $\mathrm{g}$ and $20^{\circ} \mathrm{C}$, and stored at $-80^{\circ} \mathrm{C}$ until analysis. All biochemical analyses were performed at the Neuropsychiatric Laboratory of Erasmus University Medical Center, Rotterdam, and the technician was blinded to the clinical situation and diagnosis of the patients.

Plasma was deproteinized, and amino acids were separated by high-performance liquid chromatography and detected by fluorescence after derivatization with orthophthaldialdehyde as described previously. ${ }^{37}$ HVA levels were measured after deproteinization of plasma by highperformance liquid chromatography using a Zorbax Eclipse XDB-C8 column ( $5 \mu \mathrm{m}$ particle size, $250 \times 3 \mathrm{~mm}$; Agilent Technologies, Santa Clara, CA, USA) for separation. For the detection of HVA, an electrochemical detector (oxidation potential was set to $0.7 \mathrm{~V}$ ) and the Intro controller (Antec Leyden, Zoeterwoude, the Netherlands) were used. Quantification was done by measuring peak heights relative to two internal standards (isoprenaline and 5-methylserotonin). The mean recovery ( \pm standard deviation $[\mathrm{SD}]$ ) of HVA added to the plasma samples was $95 \% \pm 7 \%$. BDNF was measured in serum by a double-antibody sandwich enzyme-linked immunosorbent assay (Promega Corporation, Madison, WI, USA).

\section{Controls}

Biochemical parameters from age-matched controls were taken from a large database of the aforementioned Neuropsychiatric Laboratory. Age-matched controls were taken from a large database, consisting of hospital staff and students and subjects from the general community, all without a personal or family history of psychiatric illness. Mean age of the control group $(n=75)$ was $37.9 \pm 10.1$ years.

\section{Statistics}

From the 58 completers, only patients with a diagnosis of schizophrenia $(n=33)$ or CP $(n=10)$ were included in the statistical analyses. To compare means, nonparametric MannWhitney $U$ test was used for non-normally distributed data (biochemical parameters), whereas Student's $t$-test was applied for normally distributed data. To investigate changes between time points, Wilcoxon signed rank test (biochemical parameters) or paired $t$-test (PANSS scores) was used. For binary variables, a chi-square test was done. Significance was set at $P<0.05$. All data are presented as mean $\pm \mathrm{SD}$, unless stated otherwise.

\section{Results Patients}

By excluding patients diagnosed with other psychotic disorders $(n=15)$, the study sample $(n=43)$ consisted of 30 males and 13 females with a mean age of $34.8 \pm 11.3$ years. Thirty-three patients received a diagnosis of schizophrenia, and in ten, a diagnosis of CP according to Leonhard was made (anxietyhappiness: $n=5$; confusion: $n=2$; motility: $n=3$ ). Mean age at first psychosis was $26.5 \pm 9.8$ years, and mean duration of psychotic illness was $8.3 \pm 8.1$ years. Fourteen patients (CP: $n=5$; schizophrenia: $n=9$ ) did not receive psychotropic medication prior to inclusion in the study (referred to as "at baseline"), of which eight were antipsychotic naïve $(C P: n=3$; schizophrenia: $\mathrm{n}=5$ ). Eight out of the total of 43 patients were first-episode psychosis (FEP) patients. Five patients were classified as both medication naïve and having FEP (CP: $n=3$; schizophrenia: $\mathrm{n}=5$ ). Details on symptom clusters, effect of antipsychotic treatment, and severity of illness are summarized in Table 2.

Since each patient received an individually targeted treatment, data were scrutinized for possible confounding effects of psychopharmacological heterogeneity. With respect to the two patient groups (CP: $n=10$; schizophrenia: $n=33$ ), no differences were found as to medication status (naïve, free $>2$ weeks, or medicated), use of co-medication (antidepressant or mood stabilizers), and antipsychotic class (FGA or SGA). Regarding the latter, in the $\mathrm{CP}$ group, none of the patients was treated with clozapine, whereas nine patients in the schizophrenia group did receive this agent. The $\mathrm{CP}$ group comprised significantly 
Table 2 Demographic and clinical parameters in patients with CP and schizophrenia

\begin{tabular}{|c|c|c|}
\hline & $C P(n=10)$ & Schizophrenia $(n=33)$ \\
\hline Male/female* & $4 / 6$ & $26 / 7$ \\
\hline Age* & $42.3 \pm 10.3$ & $32.6 \pm 10.8$ \\
\hline Age at onset* & $36.7 \pm 10.8$ & $23.4 \pm 7.1$ \\
\hline FEP, yes/no** & $5 / 5$ & $3 / 30$ \\
\hline Smoking, yes $/$ no $^{\mathrm{a}, *}$ & $3 / 7$ & $25 / 8$ \\
\hline Caffeine, yes/no ${ }^{\mathrm{a}}$ & $9 / 1$ & $29 / 4$ \\
\hline Soft drugs, yes/no ${ }^{a}$ & $1 / 9$ & $7 / 26$ \\
\hline Hard drugs, yes/no & $0 / 10$ & $2 / 31$ \\
\hline \multicolumn{3}{|l|}{ PANSS baseline ${ }^{\mathrm{b}}$} \\
\hline Total score* & $77.2 \pm 19.1$ & $92.9 \pm 17.4$ \\
\hline Positive subscale* & $20.2 \pm 5.8$ & $25.0 \pm 5.5$ \\
\hline Negative subscale** & $16.6 \pm 5.8$ & $22.9 \pm 6.8$ \\
\hline Global subscale & $40.4 \pm 11.7$ & $45.1 \pm 9.1$ \\
\hline Cognitive subscale & $13.1 \pm 4.4$ & $15.3 \pm 3.9$ \\
\hline \multicolumn{3}{|l|}{ PANSS 6 weeks ${ }^{\mathrm{b}}$} \\
\hline Total score* & $55.4 \pm 22.2$ & $75.3 \pm 13.3$ \\
\hline Positive subscale** & $11.5 \pm 6.5$ & $18.9 \pm 5.2$ \\
\hline Negative subscale* & $13.8 \pm 6.1$ & $19.4 \pm 5.1$ \\
\hline Global subscale & $30.1 \pm 11.7$ & $37.0 \pm 6.9$ \\
\hline Cognitive subscale* & $9.8 \pm 4.5$ & $13.1 \pm 3.4$ \\
\hline \multicolumn{3}{|l|}{ Mean CGI severity ${ }^{\mathrm{b}}$} \\
\hline Baseline & $4.0 \pm 1.2$ & $4.9 \pm 1.1$ \\
\hline 6 weeks* & $2.5 \pm 1.4$ & $4.0 \pm I . I$ \\
\hline Mean CGI improvement ${ }^{\mathrm{b}}$ & $2.4 \pm 1.0$ & $2.9 \pm 0.9$ \\
\hline
\end{tabular}

Notes: ${ }^{\text {aSmoking }}$ and use of caffeine/soft drugs/hard drugs were defined as any use $\neq 0$ in the past month, as reported by the patient. ${ }^{b}$ Clinical data presented as mean \pm SD. All within-group differences between PANSS and CGI scores at baseline and after 6 weeks are significant $(P \leq 0.00 \mathrm{I})$ except for PANSS negative score in the $C P$ group $(P=0.062)$. *Difference between $C P$ and schizophrenia (Mann-Whitney $U$ ), $P<0.05$. **Difference between $C P$ and schizophrenia (Mann-Whitney $U$ ), $P \leq 0.01$.

Abbreviations: CP, cycloid psychoses; FEP, first-episode psychosis; PANSS, Positive and Negative Syndrome Scale; CGI, Clinical Global Impression; SD, standard deviation.

more females, who had higher ages at first presentation of psychotic illness as well as at time of inclusion. Finally, five patients with $\mathrm{CP}$ were defined as FEP patients.

As can be inferred from Table 2, CP patients had significantly lower scores on the PANSS total, positive, and negative scale at both time points. Symptomatic improvement was most marked in the positive symptom cluster. While both groups showed symptomatic improvement after 6 weeks of treatment, a significant difference was found in PANSS cognitive score and in CGI-S for the CP group.

\section{Biochemical parameters}

As compared to controls, serum BDNF levels were lowered in patients with schizophrenia, and plasma glutamate levels appeared to be increased in both patient groups. Concerning plasma levels of glycine, significant higher values were found in CP patients at both time points as compared to patients with schizophrenia as well as control subjects. Also, at both time points, plasma tryptophan levels were significantly lower in patients with $\mathrm{CP}$ as compared to controls but differed only at baseline from the schizophrenia group. Trp/LNAAs ratio was lowered in both patient groups as compared to controls. Plasma levels of HVA did not differ between the groups. All data are presented in Table 3.

In both the subgroup of patients with schizophrenia who were treated with clozapine $(n=9)$ and the subgroup of eight medication-naïve patients (CP: $n=3$; schizophrenia: $n=5$ ), lowered serum levels of BDNF and elevated levels of glutamate were found at both time points. However, in the clozapine subgroup, glycine levels were significantly lowered as compared to controls at baseline (177.6 \pm 45.1 versus $224.2 \pm 47.8 \mu \mathrm{mol} / \mathrm{L}$ ), whereas in the medication-naïve subgroup, glycine levels did not differ from controls at both time points.

The 15 patients with diagnoses other than $\mathrm{CP}$ or schizophrenia (schizoaffective disorder: $\mathrm{n}=1$; bipolar disorder: $\mathrm{n}=5$; delusional disorder: $\mathrm{n}=1$; brief psychotic disorder: $\mathrm{n}=2$; schizotypal personality disorder: $\mathrm{n}=1$, psychotic disorder not otherwise specified: $n=5$ ) were analyzed separately. Glutamate levels were significantly elevated as compared to controls at both time points. Data on biochemical parameters in this group are depicted in Table 4.

As to intercorrelations of biochemical and clinical parameters, both in the total patient sample and in the schizophrenia subgroup, baseline glutamate levels were positively correlated with changes in PANSS cognitive scores (total sample: $T=0.280, P=0.012$; schizophrenia: $T=0.360$, $P=0.005)$. Glutamate levels after 6 weeks were positively correlated with PANSS cognitive scores at both time points in the total patient group (baseline: $T=0.221, P=0.043$; 6 weeks: $T=0.279, P=0.011)$ and with PANSS cognitive scores after 6 weeks in schizophrenia patients $(T=0.289, P=0.023)$.

Baseline glycine levels did not correlate with any of the clinical (sub)scales. Glycine levels after 6 weeks correlated significantly with changes in PANSS cognitive scores ( $T=0.523, P=0.038$ ) in $\mathrm{CP}$ patients. No other correlations were found in $\mathrm{CP}$ between glutamate or glycine levels and other PANSS or CGI scores at both time points.

No significant correlations were found for (changes in) any of the biochemical parameters from Table 3 and (changes in) other clinical parameters (PANSS or CGI) in the two subgroups at both time points.

\section{Discussion}

In this study, patients with CP and schizophrenia were assessed on both clinical and biochemical profiles. Essentially, the CP group showed better clinical outcome than the schizophrenia group and differed significantly in terms of 
Table 3 Blood levels of biochemical parameters in CP, schizophrenia, and controls

\begin{tabular}{|c|c|c|c|}
\hline & $C P(n=10)$ & Schizophrenia $(n=33)$ & Controls $(n=75)$ \\
\hline BDNF baseline $(\mu \mathrm{g} / \mathrm{L})$ & $20.4 \pm 7.1$ & $19.6 \pm 5.8 * * *$ & $24.4 \pm 6.7$ \\
\hline BDNF 6 weeks $(\mu g / L)$ & $19.9 \pm 8.1$ & $19.1 \pm 6.0 * * *$ & \\
\hline HVA baseline (nmol/L) & $60.4 \pm 21.3$ & $58.5 \pm 19.7$ & $53.4 \pm 13.7$ \\
\hline HVA 6 weeks (nmol/L) & $51.8 \pm 20.4$ & $52.1 \pm 15.8$ & \\
\hline Glutamate baseline ( $\mu \mathrm{mol} / \mathrm{L})$ & $56.3 \pm 24.8 * *$ & $69.5 \pm 30.5^{* * *}$ & $34.4 \pm 16.1$ \\
\hline Glutamate 6 weeks ( $\mu \mathrm{mol} / \mathrm{L})$ & $64.9 \pm 44.6 * *$ & $66.2 \pm 30.9 * * *$ & \\
\hline Glycine baseline $(\mu \mathrm{mol} / \mathrm{L})$ & $292.2 \pm 96.9 *$ & $215.1 \pm 62.3^{\#}$ & $224.2 \pm 47.8$ \\
\hline Glycine 6 weeks ( $\mu \mathrm{mol} / \mathrm{L})$ & $280.9 \pm 86.2 *$ & $223.7 \pm 62.3^{\#}$ & \\
\hline Tryptophan baseline ( $\mu \mathrm{mol} / \mathrm{L})$ & $37.4 \pm 14.0 * *$ & $48.3 \pm 11.5^{\#}$ & $47.5 \pm 7.7$ \\
\hline Tryptophan 6 weeks $(\mu \mathrm{mol} / \mathrm{L})$ & $38.1 \pm 10.8 * *$ & $43.5 \pm 11.7$ & \\
\hline Trp/LNAAs ratio baseline & $7.1 \pm 1.4 * *$ & $7.7 \pm 1.5^{*}$ & $8.6 \pm 1.5$ \\
\hline Trp/LNAAs ratio 6 weeks & $7.4 \pm 1.6^{*}$ & $7.8 \pm 1.7^{*}$ & \\
\hline Phenylalanine baseline $(\mu \mathrm{mol} / \mathrm{L})$ & $52.4 \pm 10.2$ & $63.4 \pm 15.1^{*, \#}$ & $56.3 \pm 8.9$ \\
\hline Phenylalanine 6 weeks $(\mu \mathrm{mol} / \mathrm{L})$ & $51.7 \pm 10.1$ & $55.3 \pm 11.2$ & \\
\hline Isoleucine baseline $(\mu \mathrm{mol} / \mathrm{L})$ & $69.1 \pm 22.1$ & $82.7 \pm 32.8$ & $71.0 \pm 22.2$ \\
\hline Isoleucine 6 weeks ( $\mu \mathrm{mol} / \mathrm{L})$ & $63.6 \pm 19.6$ & $71.8 \pm 22.1$ & \\
\hline Leucine baseline $(\mu \mathrm{mol} / \mathrm{L})$ & $121.7 \pm 36.0$ & $158.5 \pm 60.0 *$ & $130.3 \pm 32.4$ \\
\hline Leucine 6 weeks $(\mu \mathrm{mol} / \mathrm{L})$ & $123.3 \pm 39.5$ & $136.9 \pm 39.2$ & \\
\hline Valine baseline $(\mu \mathrm{mol} / \mathrm{L})$ & $218.7 \pm 65.2$ & $267.6 \pm 76.1$ & $245.3 \pm 56.6$ \\
\hline Valine 6 weeks $(\mu \mathrm{mol} / \mathrm{L})$ & $218.7 \pm 49.8$ & $239.6 \pm 58.0$ & \\
\hline Tyrosine baseline $(\mu \mathrm{mol} / \mathrm{L})$ & $61.5 \pm 14.9$ & $72.2 \pm 25.6$ & $63.9 \pm 17.0$ \\
\hline Tyrosine 6 weeks $(\mu \mathrm{mol} / \mathrm{L})$ & $61.5 \pm 18.7$ & $62.1 \pm 15.4$ & \\
\hline
\end{tabular}

Notes: *Difference versus controls (Mann-Whitney $U$ ), $P<0.05$. **Difference versus controls (Mann-Whitney $U$ ), $P \leq 0.01$. ***Difference versus controls (Mann-Whitney $U$ ), $P \leq 0.001$. "Difference between schizophrenia and CP (Mann-Whitney $U$ ), $P<0.05$. Data presented as mean \pm SD.

Abbreviations: CP, cycloid psychoses; BDNF, brain-derived neurotrophic factor; HVA, homovanillic acid; Trp/LNAAs, tryptophan/large neutral amino acids; SD, standard deviation.

biochemical parameters, particularly plasma levels of glycine and tryptophan. Serum levels of BDNF were significantly lower in the schizophrenia group as compared to controls.

With respect to glycine, in $\mathrm{CP}$, plasma levels were elevated as compared to both schizophrenia and healthy controls. Although in 2004 Sumiyoshi et al found lowered levels of glycine for schizophrenia in comparison with controls and

Table 4 Blood levels of biochemical parameters in patients with other psychotic disorders $(n=15)$ and controls $(n=75)$

\begin{tabular}{llll}
\hline & Baseline & 6 weeks & Controls \\
\hline BDNF $(\mu \mathrm{g} / \mathrm{L})$ & $21.9 \pm 8.1$ & $20.4 \pm 7.6$ & $24.4 \pm 6.7$ \\
HVA $(\mathrm{nmol} / \mathrm{L})$ & $75.5 \pm 36.6$ & $63.5 \pm 23.3$ & $53.4 \pm \mathrm{I} 3.7$ \\
Glutamate $(\mu \mathrm{mol} / \mathrm{L})$ & $51.1 \pm 13.9^{*}$ & $50.9 \pm 16.6^{*}$ & $34.4 \pm 16.1$ \\
Glycine $(\mu \mathrm{mol} / \mathrm{L})$ & $268.5 \pm 137.5$ & $263.7 \pm 124.9$ & $224.2 \pm 47.8$ \\
Tryptophan $(\mu \mathrm{mol} / \mathrm{L})$ & $47.4 \pm 9.6$ & $46.0 \pm 7.8$ & $47.5 \pm 7.7$ \\
Trp/LNAAs ratio & $7.9 \pm 2.2$ & $8.0 \pm 1.6$ & $8.6 \pm 1.5$ \\
Phenylalanine $(\mu \mathrm{mol} / \mathrm{L})$ & $59.8 \pm 12.0$ & $58.3 \pm 10.4$ & $56.3 \pm 8.9$ \\
Isoleucine $(\mu \mathrm{mol} / \mathrm{L})$ & $81.1 \pm 23.1$ & $72.7 \pm 22.3$ & $71.0 \pm 22.2$ \\
Leucine $(\mu \mathrm{mol} / \mathrm{L})$ & $149.4 \pm 43.2$ & $141.6 \pm 38.7$ & $130.3 \pm 32.4$ \\
Valine $(\mu \mathrm{mol} / \mathrm{L})$ & $264.4 \pm 52.4$ & $252.1 \pm 65.1$ & $245.3 \pm 56.6$ \\
Tyrosine $(\mu \mathrm{mol} / \mathrm{L})$ & $73.7 \pm 21 . \mathrm{I}$ & $70.5 \pm 20.7$ & $63.9 \pm 17.0$ \\
\hline
\end{tabular}

Notes: *Difference versus controls (Mann-Whitney $U$ ), $P \leq 0.00$ I. Data presented as (mean $\pm \mathrm{SD}$ ).

Abbreviations: BDNF, brain-derived neurotrophic factor; HVA, homovanillic acid; Trp/LNAAs, tryptophan/large neutral amino acids; SD, standard deviation. patients with major depression, current findings are in line with those reported in 2006 by Hoekstra et al in patients with bipolar mania. ${ }^{38,39}$

Since glycine is an essential co-agonist for glutamate at the NMDA receptor, increased levels could be regarded as a reflection of disturbances in glutamatergic neurotransmission. With respect to the latter, since plasma glutamate levels did not differ significantly between the two groups, it could be speculated that in CP, glycine levels are elevated as a compensatory reaction to NMDA receptor hypofunction, whereas patients with schizophrenia would have insufficient neuroplasticity to produce such a response. This hypothesis is corroborated by the present lowered serum BDNF levels in the schizophrenia group and by other studies showing that phencyclidine-induced psychotic symptoms can be ameliorated by administration of glycine. ${ }^{40,41}$ Further support is found in earlier studies that show beneficial effects of adjuvant high-dose glycine augmentation to other antipsychotic agents. ${ }^{42-44}$

In patients with other psychotic disorders, both BDNF and glycine levels did not differ from controls. It could be speculated that, even in the presence of sufficient neuroplasticity, the ability to adaptively increase glycine levels might be characteristic for CP. 
The observation that plasma levels of glutamate are increased in all patient groups as compared to controls is in accordance with reports that relate elevated glutamate levels with psychosis and psychotic relapse, albeit that decreased levels in schizophrenia and bipolar disorders have also been reported. ${ }^{29,45,46}$ Elevated glutamate levels are hypothesized to be the result of NMDA receptor hypofunction, leading to diminished glutamatergic neurotransmission and to the evolvement of schizophrenic symptoms, including negative and cognitive symptoms. ${ }^{15,16}$

The Trp/LNAAs ratio was significantly lower in CP and schizophrenia as compared to controls. This finding is suggestive of a decreased central serotonergic activity in both patient groups. The lower tryptophan levels in CP might point to an increased breakdown of tryptophan via the kynurenine pathway. One of the products in this pathway is kynurenic acid, which is not only an antagonist of the NMDA receptor but also a neuroprotectant. ${ }^{47,48}$ It could be speculated that in $\mathrm{CP}$, other than in schizophrenia, this neuroprotective mechanism is still activated which would correspond with better neuroplastic properties and a more favorable course of disease in CP.

Apart from small sample size and the use of peripheral measurements only, a limitation can be identified in that a substantial number of patients were treated earlier with a wide range of FGA and SGA agents. The latter, however, most probably did not interfere with the results, since no influences were found regarding medication status in the two patient groups.

\section{Conclusion}

In both $\mathrm{CP}$ and schizophrenia, systemic glutamate metabolism and the Trp/LNAAs ratio were altered, which could be related to changes in glutamate signaling. Moreover, differences in especially glycine between $\mathrm{CP}$ and schizophrenia were found, which may point at a better neuroplasticity in $\mathrm{CP}$ than in schizophrenia. This may be in line with better clinical outcome in CP. Therefore, it is crucial to identify $\mathrm{CP}$ as a separate group of disorders within the psychosis spectrum.

\section{Acknowledgments}

The authors would like to thank MKF Schneider, MD, PhD, for the critical evaluation of diagnoses in all patients and AES Sijben, $\mathrm{MSc}, \mathrm{PhD}$, for assistance with statistical analyses. The authors are indebted to Mrs A Voskuilen-Kooijman from the Neuropsychiatric Laboratory of the Department of Clinical Chemistry of the Erasmus University Medical Center for biochemical analyses.

\section{Disclosure}

The authors declare that they have no conflicts of interest in this work.

\section{References}

1. Kapur S, Mizrahi R, Li M. From dopamine to salience to psychosis linking biology, pharmacology and phenomenology of psychosis. Schizophr Res. 2005;79:59-68.

2. Javitt DC, Liederman E, Cienfuegos A, Shelley AM. Panmodal processing imprecision as a basis for dysfunction of transient memory storage systems in schizophrenia. Schizophr Bull. 1999;25:763-775.

3. Stone JM, Morrison PD, Pilowsky LS. Glutamate and dopamine dysregulation in schizophrenia - a synthesis and selective review. J Psychopharmacol. 2007;21:440-452.

4. Möhler H, Rudolph U, Boison D, Singer P, Feldon J, Yee BK. Regulation of cognition and symptoms of psychosis: focus on $\mathrm{GABA}_{\mathrm{A}}$ receptors and glycine transporter 1. Pharmacol Biochem Behav. 2008;90:58-64.

5. Gruber O, Chadha Santuccione A, Aach H. Magnetic resonance imaging in studying schizophrenia, negative symptoms, and the glutamate system. Front Psychiatry. 2014;5:32.

6. Luján R, Shigemoto R, López-Bendito G. Glutamate and GABA receptor signaling in the developing brain. Neuroscience. 2005;130:567-580.

7. Manent JB, Represa A. Neurotransmitters and brain maturation: early paracrine actions of GABA and glutamate modulate neuronal migration. Neuroscientist. 2007;13:268-279.

8. Stone JM. Glutamatergic antipsychotic drugs: a new dawn in the treatment of schizophrenia? Ther Adv Psychopharmacol. 2011;1:5-18.

9. Veerman SRT, Schulte PFJ, De Haan L. The glutamate hypothesis: a pathogenic pathway from which pharmacological interventions have emerged. Pharmacopsychiatry. 2014;47:121-130.

10. De Bartolomeis A, Sarappa C, Magara S, Iasevoli F. Targeting the glutamate system for novel antipsychotic approaches: relevance for residual psychotic symptoms and treatment resistant schizophrenia. Eur J Pharmacol. 2012;682:1-11.

11. Javitt DC, Zukin SR. Recent advances in the phencyclidine model of schizophrenia. Am J Psychiatry. 1991;148:1301-1308.

12. Dandash O, Harrison BJ, Adapa R, et al. Selective augmentation of striatal functional connectivity following NMDA receptor antagonism: implications for psychosis. Neuropsychopharmacology. 2015;40(3): 622-631.

13. Gordon JA. Testing the glutamate hypothesis of schizophrenia. Nat Neurosci. 2010;13:2-4.

14. Javitt DC. Twenty-five years of glutamate in schizophrenia: are we there yet? Schizophr Bull. 2012;38:911-913.

15. Schmitt A, Hasan A, Gruber O, Falkai P. Schizophrenia as a disorder of disconnectivity. Eur Arch Psychiatry Clin Neurosci. 2011;261: S150-S154.

16. Zink M, Englisch S, Schmitt A. Antipsychotic treatment modulates glutamate transport and NMDA receptor expression. Eur Arch Psychiatry Clin Neurosci. 2014;264:S67-S82.

17. World Health Organization. The ICD-10 Classification of Mental and Behavioural Disorders. Clinical Descriptions and Diagnostic Guidelines. Geneva: World Health Organization; 1992.

18. Leonhard K. Classification of endogenous psychoses and their differentiated etiology. New York, Springer Wien; 1999.

19. Perris C, Brockington IF. Cycloid psychoses and their relation to the major psychoses. In: Perris C, Struwe D, Jansson B, editors. Biological Psychiatry. Amsterdam: Elsevier; 1981:447-450.

20. Jabs BE, Pfuhlmann B, Bartsch AJ, Cetkovich-Bakmas MG, Stöber G. Cycloid psychoses - from clinical concepts to biological foundations. J Neural Transm. 2002;109:907-919.

21. Beckmann H, Franzek E. Cycloid psychoses and their differentiation from affective and schizophrenic psychoses. In: Henn F, Sartorius N, Helmchen H, Lauter H, editors. Contemporary Psychiatry Volume 3. Heidelberg: Springer Verlag; 2001:387-398. 
22. Jabs BE, Krause U, Althaus G, Bartsch AJ, Stöber G, Pfuhlmann B. Differences in quality of life and course of illness between cycloid and schizophrenic psychoses - a comparative study. World J Biol Psychiatry. 2004;5:136-142.

23. Salvatore P, Bhuvaneswar C, Ebert D, Maggini C, Baldessarini, RJ. Cycloid psychoses revisited: case reports, literature review, and commentary. Harv Rev Psychiatry. 2008;16:167-180.

24. American Psychiatric Association. Diagnostic and Statistic Manual of Mental Disorders (4th ed). Washington, DC: American Psychiatric Association; 1994.

25. Lindvall M, Axelsson R, Öhman, R. Incidence of cycloid psychosis: a clinical study of first-admission psychotic patients. Eur Arch Psychiatry Clin Neurosci. 1993;242:197-202.

26. Pfuhlmann B. Das Konzept der zykloiden Psychosen [The concept of cycloid psychoses]. Fortschr Neurol Psychiatr. 1998;66:1-9. German.

27. Peralta V, Cuesta MJ. Cycloid psychosis: a clinical and nosological study. Psychol Med. 2003;33:443-453.

28. Peralta V, Cuesta MJ. Cycloid psychosis. Int Rev Psychiatry. 2005;17 53-62.

29. Van der Heijden FM, Tuinier S, Fekkes D, Sijben AES, Kahn RS, Verhoeven WMA. Atypical antipsychotics and the relevance of glutamate and serotonin. Eur Neuropsychopharmacol. 2004;14:259-265.

30. Van de Kerkhof NW, Van der Heijden FM, Schneider MK, et al. Cycloid psychoses: Leonhard's descriptions revisited. Eur J Psychiatry. 2012;26:266-278.

31. Andreasen NC, Flaum MC, Arndt S. The comprehensive assessment of symptoms and history (CASH): an instrument for assessing diagnosis and psychopathology. Arch Gen Psychiatry. 1992;49:615-623.

32. Kay SR, Fiszbein A, Opfer L. The positive and negative syndrome scale (PANSS) for schizophrenia. Schizophr Bull. 1987;13:261-276.

33. Guy W. ECDEU Assessment Manual for Psychopharmacology, Revised. Bethesda, MD: National Institute of Mental Health; 1976.

34. Lindenmayer JP, Bernstein-Hyman R, Grochowski S. Five-factor model of schizophrenia: initial validation. J Nerv Ment Dis. 1994;182: 631-638.

35. Leonhard K. Differenzierte Diagnostik der endogenen Psychosen, abnormen Persönlichkeitsstrukturen und neurotischen Entwicklungen. [Differential diagnostics of endogenous psychoses, abnormal personality structures and neurotic development] 4th ed. Berlin: Verlag Gesundheit GmbH; 1991.

36. Skodol AE, Rosnick L, Kellmann D, Oldham JM, Hyler S. Development of a procedure for validating structured assessment of axis II. In: Oldham JM, editor. Personality Disorders: New Perspectives on Diagnostic Validity. Washington, DC: American Psychiatric Press; 1991:43-70.
37. Fekkes D, Van Dalen A, Edelman M, Voskuilen A. Validation of the determination of amino acids in plasma by high-performance liquid chromatography using automated pre-column derivatization with o-phthaldialdehyde. J Chromatogr B Biomed Appl. 1995;669(2):177-186.

38. Sumiyoshi T, Anil AE, Jin D, Jayathilake K, Lee M, Meltzer HY. Plasma glycine and serine levels in schizophrenia compared to normal controls and major depression: relation to negative symptoms. Int J Neuropsychopharmacol. 2004;7:1-8.

39. Hoekstra R, Fekkes D, Loonen AJM, Pepplinkhuizen L, Tuinier S, Verhoeven WMA. Bipolar mania and plasma amino acids: increased levels of glycine. Eur Neuropsychopharmacol. 2006;16:71-77.

40. D'Souza DC, Singh N, Elander J, et al. Glycine transporter inhibitor attenuates the psychomimetic effects of ketamine in healthy males: preliminary evidence. Neuropsychopharmacology. 2012;37:1036-1046.

41. Woods SW, Walsh BC, Hawkins KA, et al. Glycine treatment of the risk syndrome for psychosis: report of two pilot studies. Eur Neuropsychopharmacol. 2013;23:931-940.

42. Heresco-Levy U, Javitt DC, Ermilov M, Mordel C, Horowitz A, Kelly D. Double-blind, placebo-controlled, crossover trial of glycine adjuvant therapy for treatment-resistant schizophrenia. $\mathrm{Br} J$ Psychiatry. 1996;169:610-617.

43. Heresco-Levy U, JavittDC, Ermilov M, MordelC, Silipo G, Lichtenstein M. Efficacy of high-dose glycine in the treatment of enduring negative symptoms of schizophrenia. Arch Gen Psychiatry. 1999;56:29-36.

44. Heresco-Levy U, Ermilov M, Lichtenberg P, Bar G, Javitt DC. Highdose glycine added to olanzapine and risperidone for the treatment of schizophrenia. Biol Psychiatry. 2004;55:165-171.

45. Ivanova SA, Boyko AS, Fedorenko OY, Krotenko NM, Semke AV, Bokhan NA. Glutamate concentration in the serum of patients with schizophrenia. Procedia Chem. 2014;10:80-85.

46. Palomino A, González-Pinto A, Aldama A, et al. Decreased levels of plasma glutamate in patients with first-episode schizophrenia and bipolar disorder. Schizophr Res. 2007;95:174-178.

47. Anderson G, Maes M. Schizophrenia: linking prenatal infection to cytokines, the tryptophan catabolite (TRYCAT) pathway, NMDA receptor hypofunction, neurodevelopment and neuroprogression. Prog Neuropsychopharmacol Biol Psychiatry. 2013;42:5-19.

48. Hashimoto K. Targeting of NMDA receptors in new treatments for schizophrenia. Expert Opin Ther Targets. 2014;18:1049-1063.
Neuropsychiatric Disease and Treatment

\section{Publish your work in this journal}

Neuropsychiatric Disease and Treatment is an international, peerreviewed journal of clinical therapeutics and pharmacology focusing on concise rapid reporting of clinical or pre-clinical studies on a range of neuropsychiatric and neurological disorders. This journa is indexed on PubMed Central, the 'PsycINFO' database and CAS,

\section{Dovepress}

and is the official journal of The International Neuropsychiatric Association (INA). The manuscript management system is completely online and includes a very quick and fair peer-review system, which is all easy to use. Visit http://www.dovepress.com/testimonials.php to read real quotes from published authors. 